\title{
定温 DTAによる結晶成長速度の評価†
}

\author{
若杉隆*問口卓 矢** \\ 田中勝 久** 大田陸 夫*
}

\section{Evaluation of Crystal Growth Rate by Isothermal DTA}

\author{
by \\ Takashi WAKASUGI ${ }^{*}$, Takuya KAdOGUCHI ${ }^{* *}$, \\ Katsuhisa TANAKA ${ }^{* *}$ and Rikuo OTA ${ }^{*}$
}

\begin{abstract}
Isothermal DTA was performed at various temperatures for nucleated $\mathrm{Li}_{2} \mathrm{O} \cdot 2 \mathrm{SiO}_{2}$ glasses and the time neccesary to obtain crystallization peak, $t_{0}$, was measured. The number density of nuclei in the glass was evaluated from crystallization peak temperature, $T_{\mathrm{C}}$, obtained by DTA with the heating rate of $10^{\circ} \mathrm{C} / \mathrm{min}$. The crystal growth rate of $\mathrm{Li}_{2} \mathrm{O} \cdot 2 \mathrm{SiO}_{2}$ glass was calculated from $t_{0}$ and $T_{\mathrm{C}}$. By this method, crystal growth rate was measured more conveniently than by the traditional method based on the observation by micsroscope. The accuracy of crystal growth rate obtained was discussed, and it was found that good accuracy is attainable by using the glass samples with proper number density of nuclei.
\end{abstract}

Key words : Crystal growth rate, Crystallization, Isothermal DTA, $\mathrm{Li}_{2} \mathrm{O} \cdot 2 \mathrm{SiO}_{2}$ glass

\section{1 緒言}

ガラスの結晶化は, 核生成とその成長により進行する. 従って, 結晶化機構を考察する上で, 核生成と結晶成長 を理解することが不可欠である。これまでに，様々な研

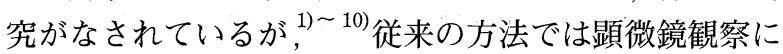
より核の数や結晶の大きさを測定する必要があった。こ の方法は直接観察を行うという点で確実な方法であるが, 顕微鏡の解像度に限界があるため, 結晶成長速度の小さ な領域では生成した核を観察可能な大きさまで成長させ るという，余分な手順が必要になる。また，顕微鏡観察 を行うために試料の前処理等の煩雑な処理が必要になる.

これに対して示差熱分析 (DTA) や示差走査熱量測定 (DSC) を用いて, 結晶化過程を調べる方法が提案されて いる. Marotta ら ${ }^{11)}$ は核生成熱処理を施した $\mathrm{Li}_{2} \mathrm{O}$ ・ $2 \mathrm{SiO}_{2}$ ガラスの DTA 測定を行い, 得られた結晶化ピーク 温度の逆数が核生成量に対応すると報告した. Ray ${ }^{12)}$ は結晶化ピーク温度の逆数以外にピーク高さ，半值幅な どのパラメータを比較し, ピーク高さが核生成量の指標 として適していると報告した。これらの報告では核生成 量を定性的にしか評価できないが，著者らは，同じ結晶 化ピーク温度を持つ試料中の核生成量は等しいと考えて, 異なる温度での核生成速度を半定量的に評価することに 成功している.

一方，DTAによる結晶成長速度の評価に関しては報告 が少ない.Day らは近年 DTA 装置内で核生成, 結晶成 長を行わせたときに得られた DTAの結晶化ピーク面積 を用いて, 核生成速度と結晶成長速度を同時に求める手

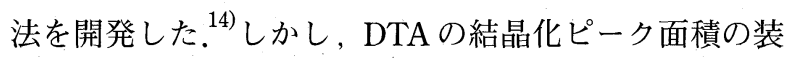
置の熱容量や断熱性などへの依存性等について議論され ていない. また, この手法で求められた結晶成長速度と, 直接観察による測定值との間に十分な一致が見られてい るとは言い難い.

本研究では, 定温 DTA 測定において結晶化ピークが 現れるまでの時間から結晶成長速度を算出する方法につ いて，検討を行った。核生成熱処理を施した $\mathrm{Li}_{2} \mathrm{O}$ ・ $2 \mathrm{SiO}_{2}$ ガラスを用いて定温 DTA 測定により結晶成長速度 の測定を行い，その精度について評価を行った。

\section{2 実 験 方 法}

試薬特級の $\mathrm{Li}_{2} \mathrm{CO}_{3}$ と $\mathrm{SiO}_{2}$ を所定組成に混合し，白金 るつぼを用い, 大気䨌囲気下， $1300^{\circ} \mathrm{C} て ゙ 1$ 時間溶融した。 均一なガラスを得るために, 溶融中に数回融液を摚拌し た.これを銅板上に流し出し，もう一枚の銅板で厚さ約 $2 \mathrm{~mm}$ にプレスすることにより急冷しガラス試料を得た. このガラス試料を $10 \mathrm{~mm}$ 角程度の大きさに割り, $460^{\circ} \mathrm{C}$ で 20 ないし 144 時間熱処理を行い核生成させた，表面 核生成の影響を除くために表面を研削し，一辺が約 $2 \mathrm{~mm}$ の立方体に成形した後に定温 DTA 測定に用いた.

定温 DTA 測定には RIGAKU 製 Thermoflex TG-8110 を用いた，定温 DTA 測定では試料をできるだけ短時間 で所定温度まで昇温する必要があるが, 本装置に付属の 昇温プログラムの最大昇温速度は $20^{\circ} \mathrm{C} / \mathrm{min}$ であり, 本 実験の目的には不十分であった。そのため, 装置をあら かじめ昇温させ, 所定温度で 30 分間保持した後に試料 を装置上部より投入するという方法を採用した。試料を

$\dagger \quad$ 原稿受理 平成 14 年 9 月 13 日 Received Sep. 13, 2002

* 正 会員 京都工芸繊維大学工芸学部物質工学科 †606-8585 京都市左京区松ヶ崎, Dept. Chem. \& Mater. Tech., Kyoto Inst. of Tech., Sakyo-ku, Kyoto, 606-8585

** 京都工芸繊維大学工芸学部物質工学科７606-8585 京都市左京区松ヶ崎, Dept. Chem. \& Mater. Tech., Kyoto Inst. of Tech., Sakyo-ku, Kyoto, 606-8585 
投入すると，DTAの試料側の温度は最初低下するが，試 料温度が上昇するに従い，試料投入後の数秒から約 10 秒後に上昇しはじめる。温度が上昇に転じたときから結 晶化ピークが現れるまでの時間， $t_{0}$ を測定した．本装置 の試料部は Fig. 1 に示すようにアルミナ管に覆われてお り，そのままでは試料を上部から投入することが不可能 なので，アルミナ管の上部を切断して実験を行った.

また，核生成熱処理を行った試料中に存在する核の数 密度を求めるために，定温 DTA に用いる試料と同様に 整形した試料について $10^{\circ} \mathrm{C} / \mathrm{min}$ の昇温速度で DTA 測定 を行い, 結晶化ピーク温度, $T_{\mathrm{C}}$ を求めた.

\section{$3 \cdot 1$ 等温 DTA 曲線}

$460^{\circ} \mathrm{C}$ 144 時間熱処理を行った試料について，578〜 $598^{\circ} \mathrm{C}$ での定温 DTA 曲線を Fig. 2 に示す。横軸は，試 料投入後に低下し始めた試料部温度が上昇に転じた時か らの経過時間である。測定初期において DTA 曲線が急 激に立ち上がるのは，試料が急速に加熱されているため である．温度が低いと結晶化ピークはなだらかになり $t_{0}$ は長くなったが, 温度が高くなると結晶化ピークは鋭く なり $t_{0}$ は短くなった。 今回得られた $t_{0}$ を Table I に示す.

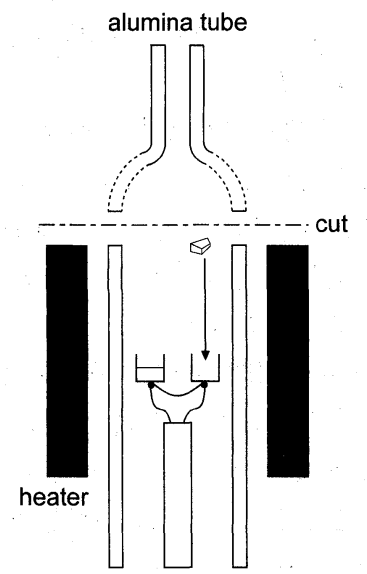

Fig. 1. Cross section of DTA apparatus.

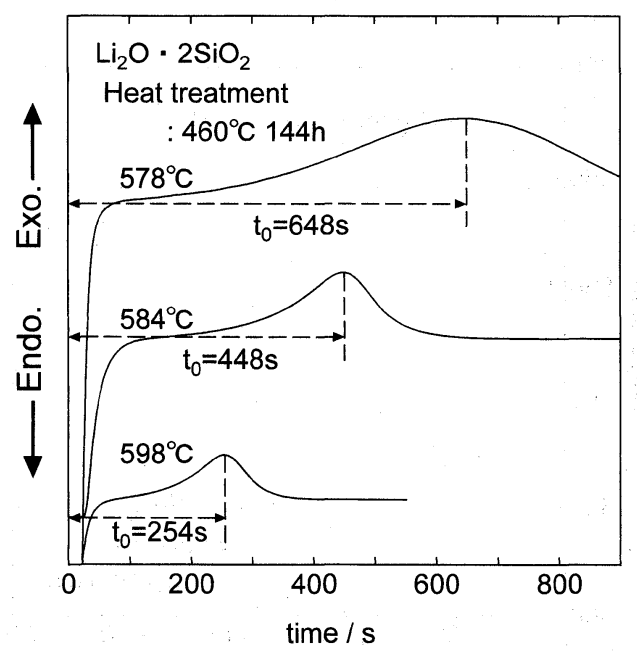

Fig. 2. Isothermal DTA curves for $\mathrm{Li}_{2} \mathrm{O} \cdot 2 \mathrm{SiO}_{2}$ glass nucleated at $460^{\circ} \mathrm{C}$ for $144 \mathrm{~h}$.
Table I. Time required to obtain crystallization peak in isothermal DTA measurement for $\mathrm{Li}_{2} \mathrm{O} \cdot 2 \mathrm{SiO}_{2}$ glass nucleated at $460^{\circ} \mathrm{C}$.

\begin{tabular}{|c|c|c|c|}
\hline $\begin{array}{c}\text { Nucleation } \\
\text { time }\end{array}$ & $\begin{array}{c}\text { DTA } \\
\text { Temperature }\end{array}$ & $t_{0} / \mathrm{s}$ & $U / \mathrm{m} \cdot \mathrm{s}^{-1}$ \\
\hline \multirow{4}{*}{$144 \mathrm{~h}$} & $560^{\circ} \mathrm{C}$ & 1598 & $3.33 \times 10^{-9}$ \\
\cline { 2 - 4 } & $578^{\circ} \mathrm{C}$ & 648 & $8.20 \times 10^{-9}$ \\
\cline { 2 - 4 } & $584^{\circ} \mathrm{C}$ & 448 & $1.19 \times 10^{-8}$ \\
\cline { 2 - 4 } & $598^{\circ} \mathrm{C}$ & 254 & $2.09 \times 10^{-8}$ \\
\hline \multirow{6}{*}{$20 \mathrm{~h}$} & $601^{\circ} \mathrm{C}$ & 358 & $2.73 \times 10^{-8}$ \\
\cline { 2 - 4 } & $612^{\circ} \mathrm{C}$ & 298 & $3.28 \times 10^{-8}$ \\
\cline { 2 - 4 } & $619^{\circ} \mathrm{C}$ & 208 & $4.70 \times 10^{-8}$ \\
\cline { 2 - 4 } & $625^{\circ} \mathrm{C}$ & 172 & $5.67 \times 10^{-8}$ \\
\cline { 2 - 4 } & $640^{\circ} \mathrm{C}$ & 94 & $1.04 \times 10^{-7}$ \\
\hline
\end{tabular}

熱処理時間が 20 時間の試料の定温 DTA は 144 時間の試 料よりも高い温度で行った。これは 144 時間の試料につ いて高い温度域で定温 DTA 測定を行うと結晶化が急激 に進行し，昇温過程中の結晶成長が無視できなくなるた めである. 逆に 20 時間の試料について低温域で定温 DTA を行うと結晶化ピークは小さくなだらかになってし まい， $t_{0}$ が精度よく決定できなかった。

\section{$3 \cdot 2$ 結晶成長速度の導出}

ガラス中の結晶核が球状であり等方的に成長する場合， 結晶核の数密度が $N$, 半径が $r$ である時の結晶化分率, $\alpha$ は式 (1)で表される。

$$
\alpha=1-\exp \left(-\frac{4}{3} \pi N r^{3}\right)
$$

定温 DTA を行う温度 $T$ に打ける結晶成長速度を $U$ と すると, DTA 測定前の核の半径を無視するならば $r=U t$ である。ここで, $t$ は定温 DTA 測定開始からの経過時間 であり, 試料温度は室温から瞬時に $T$ に到達すると仮定 する．DTA 測定における試料の温度上昇は単位時間あた りに結晶化した量に比例するので，DTA曲線は式 (2)で 表される。

$$
\frac{d \alpha}{d t}=4 \pi N U r^{2}(1-\alpha)
$$

定温 DTA 測定中に結晶化が進行し，時刻 $t=t_{0}$ にお いて結晶化ピークが得られるが，このとき $\alpha$ の時間に対 する二階微分が 0 となる． $\alpha$ の二階微分は式 (3)である. $r=U t_{0}$ を代入し, 式 (3)を 0 とおいて整理すると式 (4) が得られる. 従って, 結晶成長速度 $U$ は式 (5)で求めら れる。

$$
\begin{aligned}
& \frac{d^{2} \alpha}{d t^{2}}=8 \pi N U^{2} r(1-\alpha)-16 \pi^{2} N^{2} U^{2} r^{4}(1-\alpha)=0 \\
& 1-2 \pi N\left(U t_{0}\right)^{3}=0 \\
& U=\sqrt[3]{\frac{1}{2 \pi N}} \times \frac{1}{t_{0}}
\end{aligned}
$$

従って, 試料中に存在する核の数密度， $N$ を知ること により，測定で得られた $t_{0}$ から結晶成長速度を求めるこ とができる. 


\section{$3 \cdot 3$ 核の数密度の見積もり}

著者らは，様々な核生成熱処理を施した $\mathrm{Li}_{2} \mathrm{O} \cdot 2 \mathrm{SiO}_{2}$ ガラスについて $10^{\circ} \mathrm{C} / \mathrm{min}$ の昇温速度で DTA 測定を行 い, 結晶化ピーク温度， $T_{C}$ を測定した。 その結果， $T_{\mathrm{C}}$ と核の数密度，Nの間には式 (6)で表される良好な相関 性があることを見いだした. ${ }^{15}$

$$
\log N=-0.6698 T \mathrm{c}+56.38 \pm 0.1
$$

ここで, $N$ と $T_{\mathrm{C}}$ の単位はそれぞれ $\left[\mathrm{m}^{-3}\right]$ と $\left[{ }^{\circ} \mathrm{C}\right]$ である

20 時間および 144 時間の核生成熱处理を施した試料の

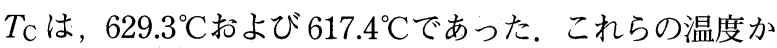
ら式 (6) を用いて求めた核の数密度は，20 時間抢よび 144 時間の試料でそれでれ $1.7 \times 10^{14}$ 打よび $1.1 \times$ $10^{15} / \mathrm{m}^{3}$ であった。

\section{$3 \cdot 4$ 結晶成長速度}

前節までで得られた結晶化ピーク温度， $T_{\mathrm{C}}$ と核の数密 度， $N$ を用いて得られた結晶成長速度を Fig. 3 に示す。 結晶成長速度は温度の上昇とともに増加した. Fig. 3 に はこれまでに報告されている, 顕微鏡観察によって求め られた結晶成長速度の文献值を併せて示したが，今回定 温 DTA により求めた值はそれらの値によく一致した。

結晶成長速度についてはいくつかの式が提案されてい るが, 式 (7)はその一つである.

$$
U=\frac{c}{\eta}\left[1-\exp \left(\frac{\Delta H_{\mathrm{m}}\left(T-T_{\mathrm{m}}\right)}{R T T_{\mathrm{m}}}\right)\right]
$$

ここで， $\eta, \Delta H_{\mathrm{m}}, T_{\mathrm{m}}$ はそれぞれ，粘度，結晶の融解 エンタルピーおよび融点であり, $c$ は定数である。この 定数は拡散係数や流動単位などを含む。結晶成長速度式 を厳密に考えるにはもっと複雑な式が必要になるので, 式 (7)は温度依存性を表すための簡易的なものである.

今回得られた結晶成長速度の温度依存性を, 最小二乗 法を用いて式 (7) にフィッティングさせたところ,$c$ の値 として 0.146 を得た。 以前, 著者らは $\mathrm{Li}_{2} \mathrm{O} \cdot 2 \mathrm{SiO}_{2}$ ガラ スにおける核の数密度と結晶化ピーク温度の関係を, 結 晶化過程の数值解析の結果と比較することにより $\mathrm{c}$ の值

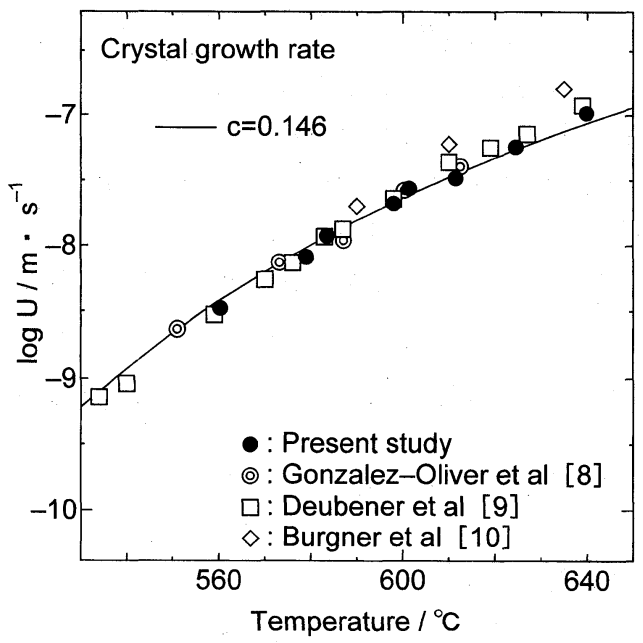

Fig. 3. Temperature dependence of crystal growth rate for $\mathrm{Li}_{2} \mathrm{O} \cdot 2 \mathrm{SiO}_{2}$ glass.
を 0.209 と求めた ${ }^{17)}$ しかしこの值は結晶化ピーク温度に よる依存性が見られたため, 結果としてある温度域の平 均值という形で求められていた。そのため実測值よりも 少し大きな計算值が得られたが, 今回得られた $c=0.146$ という值では実測値と非常によい一致が得られた。

\section{$3 \cdot 5$ 定温 DTA における誤差の評価}

定温 DTA の結果の解析に抢いて，試料が DTA に投入 後ただちに保持温度に到達し，その温度で保持されるこ とが仮定されている。しかし現実には試料が保持温度に 到達するまでには一定の時間を要する，そのため，仮定 した条件よりもその間の成長量は少なくなるために，実 測した $t_{0}$ から式 (5)により求められる結晶成長速度は, 真の值よりも低くなる. 測定された $t_{0}$ に対して保持温度 に達するまでの時間の割合が低ければ，この誤差の影響 は小さくなる。しかし，温度が高くなり $t_{0}$ が短くなると， この誤差は無視できない．本実験では，DTAの試料部に 試料投入する事により低下しはじめた温度が上昇に転じ る時を $t_{0}$ 測定の開始点としている. このときの温度は平 均して設定温度よりも約 $40^{\circ} \mathrm{C}$ 低い. $\mathrm{Li}_{2} \mathrm{O} \cdot 2 \mathrm{SiO}_{2}$ ガラス の結晶成長速度に関するこれまでの報告值を見ると約 $40^{\circ} \mathrm{C}$ 低下寸ると結晶成長速度は約 1 けた低下しており, 試料が室温からこの温度まで上昇する際の結晶成長は無 視できると考えている. $t_{0}$ 測定の開始以降の温度上昇を 示したのが Fig. 4 である.

約 30 秒で所定温度の $5^{\circ} \mathrm{C}$ 以内に到達している。この間 の結晶成長は所定温度でのそれよりも小さいので，式 (5) の導出で用いているように，「試料か瞬時に設定温度に昇 温される」と仮定した場合に期待される $t_{0} よ り も ，$ 実測 される $t_{0}$ は長くなってしまう。この誤差を正確に評価す ることは難しいが, 初期の 30 秒間に結晶成長が進行し ないと仮定することにより，考え得る最大の誤差を見積 もることができる。このようにして見積もられる誤差は $t_{0}$ が短いほど大きくなり，本実験で最短の $t_{0}$ が得られた $640^{\circ} \mathrm{C}$ では約 $30 \%$ に達する。一方で， $t_{0}$ が 300 秒以上で あれば，誤差は $10 \%$ 以下になる。 Fig. 3 に示すように。 今回得られた結晶成長速度は長い $t_{0}$ が得られた低温域で

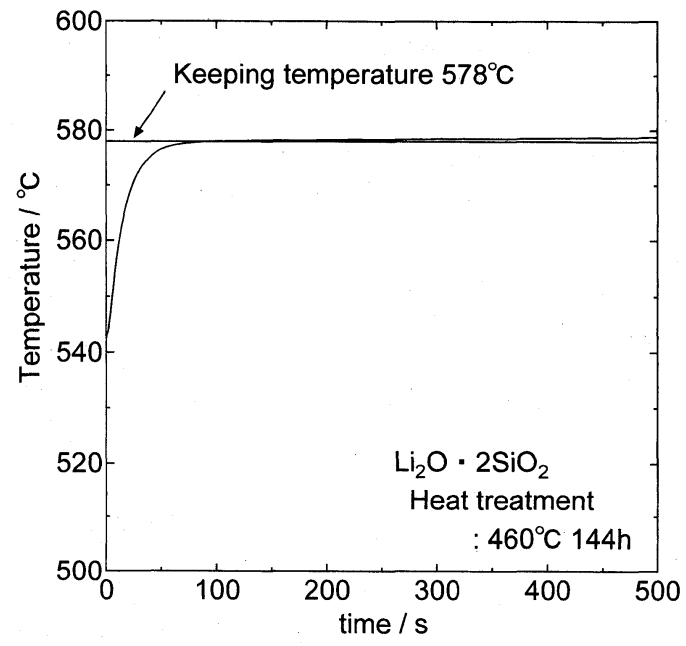

Fig. 4. Variation of temperature during isothermal DTA. 
は文献值と非常によく一致するが， $t_{0}$ が短くなる高温域 ではやや低めの值が得られており, 上述の考察に定性的 に一致する。

今回の測定では高温域で測定誤差が大きくなったが， ガラス試料中の核の数密度を低くすることにより $t_{0}$ を長 くすることが可能である.したがって，測定温度範囲によ りきめ細かく試料中の核の数密度を変化させることによ り, 精度よく結晶成長速度を測定することが可能である.

\section{4 結}

\section{言}

あらかじめ核生成熱処理を施した $\mathrm{Li}_{2} \mathrm{O} \cdot 2 \mathrm{SiO}_{2}$ ガラス を対象に，定温 DTAにより結晶化ピークが得られるま での時間， $t_{0}$ の測定を行った。この值とガラス中に存在 する核の数密度から, 結晶成長速度を求めた. $t_{0}$ は定温 DTA の保持温度の上昇, および核の数密度の増加により 短くなった。得られた結晶成長速度は，これまでに報告 されている顕微鏡を用いた直接観察による測定值によく 一致した。この方法で求められる結晶成長速度の精度は $t_{0}$ の長さに依存し，長いほざ精度はよくなる，ガラス中 に存在する核の数密度を適当に選択することにより, 広 い温度範囲で精度よく結晶成長速度を測定できることが 明らかになった。

\section{参考 文 献}

1) J. G. Morley, Br. J. Appl. Phys., 12, 10 (1961).

2) T. Ogura, R. Hayashi and M. Kodama, J. Ceram. Soc. Jpn., 76, 277 (1968).
3) K. Nakagawa and T. Izumitani, Phys. Chem. Glasses, 10, 179 (1969).

4 ) M. Tomozawa, Phys. Chem. Glasses, 14, 112 (1973).

5 ) K. Matusita and S. Sakka, Phys.Chem. Glasses, 14, 77 (1973).

6) K. Matusita and S. Sakka, J. Non-Cryst. Solids, 11, 471 (1973).

7 ) P. F. James, Phys. Chem. Glasses, 15, 95 (1974).

8 ) C. J. R. Gonzalez-Oliver, P. S. Johnson and P. F. James, J. Mater. Sci., 14, 1159 (1979).

9) J. Deubener, R. Brucker and M. Stainitzke, J. Non- Cryst. Solids, 163, 1 (1993).

10) L. L. Burgner and M. C. Weinberg, J. Non-Cryst. Solids, 279, 28 (2001).

11) A. Marotta, A. Buri, F. Branda and S. Saiello, "Advances in Ceramics, Vol.4, Nucleation and Crystallization in Glasses", Ed. By J. H. Simmons. D. R. Uhlmann and G. H. Beall, p.146 (1982) American Ceramic Society.

12) D. E. Day, J. Am. Ceram. Soc., 73, 439 (1990).

13) T. Wakasugi, L. L. Burgner and M. C. Weinberg, J. NonCryst.Solids, 244, 63 (1999).

14) C. S. Ray, X. Fang and D. E. Day, J. Am. Ceram. Soc., 83, 865 (2000).

15) T. Wakasugi, T. Kadoguchi and R. Ota, J. Non-Cryst. Solids, 290, 64 (2001).

16) H. Scholze, "Glass”, p.64 (1991) Springer.

17) T. Wakasugi and R. Ota, J. Non-Cryst. Solids, 274, 175 (2000). 